\title{
Effect of Growth Regulators on In-vitro Shooting of Calathea ornata for Commercial Cultivation
}

\author{
G. H. N. Maheepala ${ }^{1}$, D. de Silva ${ }^{2}$, P. E. Kaliyadasa ${ }^{1 *}$ and G. Y. A. D. D. Perera ${ }^{1}$
}

\begin{abstract}
Calathea ornata is a member of the family Marantaceae, with glossy, leathery leaves in attractive dark or olive green colors. Its uniquely patterned feathered or fish-bone design of distinct white lines makes it a high demand in the foliage industry as a house plant. The aim of this study was to develop a shoot induction protocol with efficient sterilization technique, best explant type and different combination of growth regulators as a cost-effective method for commercial invitro propagation. Meristem tissue of $\mathrm{C}$. ornata was successfully established with minimum contamination percentage, by following the protocol developed for surface sterilization, using stepwise rinsing with several disinfections. Different concentrations of BAP (6-Benzyl Amino Purine) and NAA (Naphthalene Acetic Acid) were tested for explant initiation and multiplication in ten replicates. The data were analyzed using ANOVA in Complete Randomized Design. The highest number of shoots was induced on MS basal media supplemented with $3.0 \mathrm{mgL}^{-1}$ BAP and 3.5 mgL $^{-1}$ NAA. Subsequently, initiated shoots
\end{abstract}

\footnotetext{
${ }^{1}$ Department of Export Agriculture, Uva Wellassa University, Passara Road, Badulla, Sri Lanka

${ }^{2}$ Serendib Horticulture Technologies (Pvt) Ltd, Boralesgamuwa, Sri Lanka

*ewon101k@yahoo.com
}

http://orcid.org/0000-0003-4684-0024

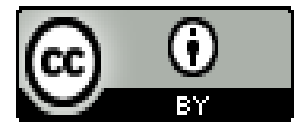

This article is published under the terms of the Creative Commons Attribution 4.0 International License, which permits unrestricted use, distribution and reproduction in any medium provided the original author and source are credited. were sub-cultured for shoot multiplication and the highest number of shoots and shoot length were observed in MS media in combination with BAP $3.0 \mathrm{mgL}^{-1}$ with NAA $3.5 \mathrm{mgL}^{-1}$. Above stated effective sterilization and shoot multiplication protocols could be used in commercial in-vitro propagation of Calathea ornata.

Keywords: BAP, In-vitro, Marantaceae, Meristem, NAA, Sterilization

\section{INTRODUCTION}

In horticultural terms, foliage plants are those with attractive foliage and/or flowers that are produced in containers used primarily as living specimens for interior decoration or interior-scaping (Chen et al., 2002). In common terminology, foliage plants are referred to as houseplants. With the increasing demand for foliage plants, it becomes a highly profitable industry with improvement of the standard of living day by day (Griffith, 1998). Higher usage of foliage plants in hotels, restaurants and the influx of tourists create more marketing opportunities and higher profit (Yang et al., 1998). Due to the high income generating potential, foliage plant industry is considered as an agribusiness venture that enable the socioeconomic development of a country (Chen et al., 2005).

Variegated plants comprise about one third of the ornamental plants grown 
commercially (Betrock, 1996). Due to their attractive multi-colored leaves, variegated foliage plants such as Aglaonema, Calathea, Cordyline, Diffenbachia, Dracaena, and Syngonium are widely used in interior plant-scape (O'Riordain, 1999).

Calathea ornata belongs to the Marantaceae plant family, a high value ornamental plant characterized by large, elliptical, glossy and leathery leaves that are dark or olive green above leaf surface and uniquely patterned with a feathered or fishbone design of distinct white lines, occasionally with pink overtones (Anon, 2003). The pink tint tends to fade as the plant matures. The underside of each leaf is maroon or plum red. Their eye catchy broad blades are emerged from the crown (Anon, 2003).

Like many species of the Marantaceae family, C. ornata also has the characteristic feature of folding up their leaves like hands held upright in prayer (Podwyszy'nska, 1997). This plant looks attractive at indoors but it is also possible to maintain outdoors such as patios, porches and decking. It can also be planted in beds and borders too (Anon, 2003).

C. ornata is traditionally propagated through vegetative techniques using the cutting of rhizomes. However, this propagation technique shows very slow growth rate which takes long time for largescale multiplication (Scaramuzzi and Apollinio, 1997). An efficient multiplication method is required to continuous supply of disease-free plants in large scale commercial venture using invitro propagation (Daquinta et al., 2009). The production of micro-cuttings with high quality plantlets that are suitable for transplanting into the natural environment was especially in demand. There has been less information in literature on in-vitro propagation of species of Marantaceae family (Dunston and Sutter, 1984; VanMil and VanTelgen, 1990).

In view of this importance of $C$. ornata plant as a foliage plant and advantages of plant tissue culture as a rapid multiplication technique used in commercial horticultural sector, this study aimed to determine the effective aseptic technique in micropropagation method of $C$. ornata and to establish a successful growth hormonal combination to gain higher number of shoots that can be effectively used in commercial scale cultivation.

\section{MATERIALS AND METHODS}

\section{Explants Collection and Surface Sterilization}

Mature and healthy mother plants of $C$. ornata were obtained from mother plant nursery (Plate 01 ) of Serendib Horticulture Technologies (Pvt) Ltd, Boralesgamuwa, Sri Lanka. Meristem tissues that appeared from the cleaned rhizomes of the mother plants were used as the sources of explant for the study.

Mother plant were collected and washed with detergent Teepol for one hour under running tap water to remove any soil particles and plant debries attached to the 
rhizomes of mother plants. The external leaves were removed and the shoot buds were trimmed down until the size ranged from 1.5 to $2.0 \mathrm{~cm}$.

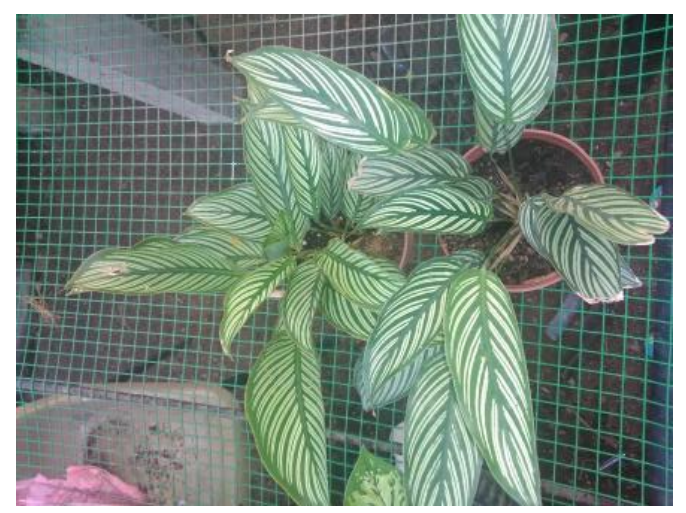

Plate 1. Mother plant of Calathea ornata

Primarily surface sterilized explants were again surface sterilized under aseptic conditions, with three different disinfectants as shown in Table 1 by following the general sterilization method summarized in Figure 1. Each disinfectant was added together with one or two drops of Tween 20 to reduce surface tension.

\section{Establishment of Explants}

Surface sterilized explants were introduced to the modified MS liquid media. Half strength MS with $1 \mathrm{mgL}^{-1}$ BAP and 0.1 $\mathrm{mgL}^{-1}$ NAA was used to check the viability and consistency of the explants. Then liquid cultured explants were kept one week for 24 $\mathrm{h}$ photoperiod under the cool white fluorescent lamp with 2000 lux. After one week, number of non-contaminated explants were recorded.

\section{Initiation of Multiple Shoots}

MS basal medium consisted with different combinations of BAP and NAA were prepared to inoculate the non-contaminated explants for shoot initiation, as shown in Table 2. These media were adjusted to $\mathrm{pH}$ 5.8 prior to autoclave at $121{ }^{\circ} \mathrm{C}$ for $15 \mathrm{~min}$. Cultures were properly labeled and maintained in the growth room with $16 / 8 \mathrm{~h}$ photoperiod at $25 \pm 2{ }^{\circ} \mathrm{C}$.

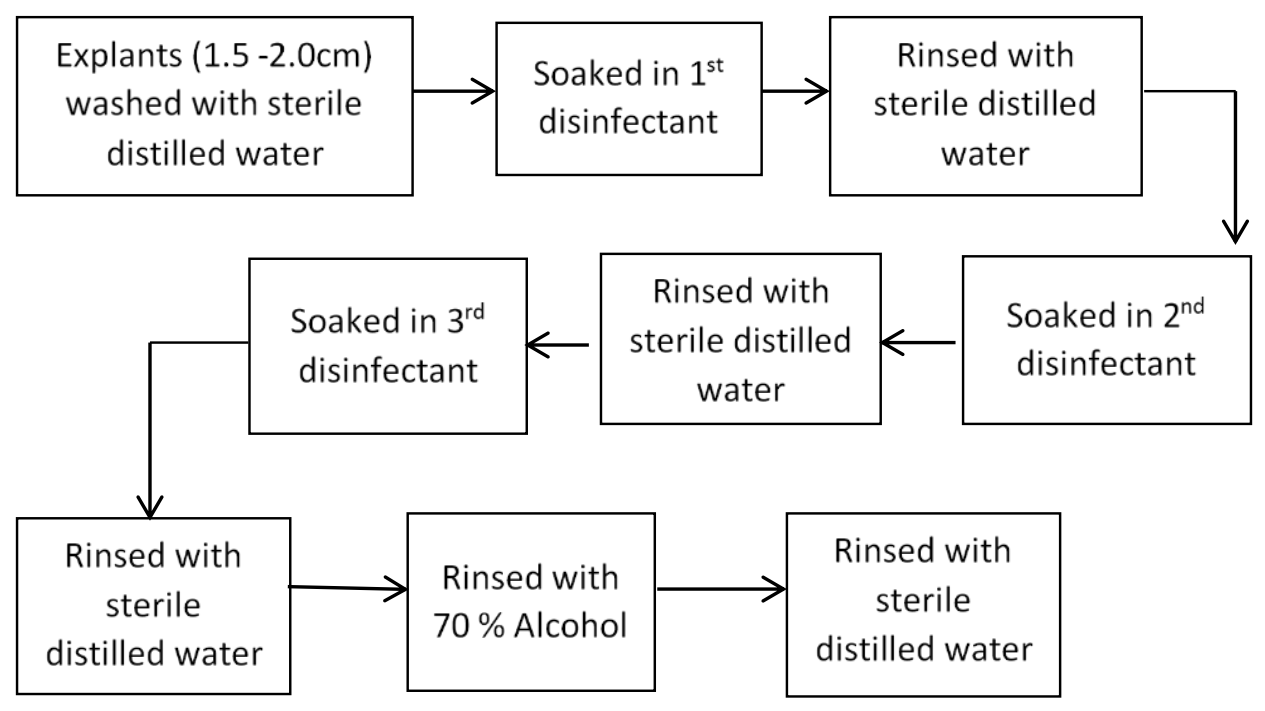

Figure 1. General sterilization protocol for explants of Calathea ornata 
G. H. N. Maheepala, D. de Silva, P. E. Kaliyadasa and G. Y. A. D. D. Perera

Table 1. Three different disinfectants in surface sterilization for explants of C. ornata

\begin{tabular}{cccc}
\hline Treatment & $\begin{array}{c}\text { Disinfectant 1 } \\
\text { (Ethanol) }\end{array}$ & $\begin{array}{c}\text { Disinfectant 2 } \\
(\mathbf{H g C l})\end{array}$ & $\begin{array}{c}\text { Disinfectant 3 } \\
(\mathbf{N a O C l})\end{array}$ \\
\hline Treatment 1 $\left(\mathrm{T}_{1}\right)$ & $70 \%(1.0 \mathrm{~min})$ & $15 \%(15 \mathrm{~min})$ & $20 \%(10 \mathrm{~min})$ \\
\hline Treatment 2 $\left(\mathrm{T}_{2}\right)$ & $70 \%(1.5 \mathrm{~min})$ & $20 \%(15 \mathrm{~min})$ & $20 \%(10 \mathrm{~min})$ \\
\hline Treatment 3 $\left(\mathrm{T}_{3}\right)$ & $70 \%(2.0 \mathrm{~min})$ & $25 \%(15 \mathrm{~min})$ & $20 \%(10 \mathrm{~min})$ \\
\hline
\end{tabular}

Table 2. Different hormonal combinations for shoot initiation

\begin{tabular}{cccccc}
\hline \multirow{2}{*}{ Hormone } & \multicolumn{5}{c}{ Media $\left(\mathbf{m g L}^{-\mathbf{1}}\right)$} \\
\cline { 2 - 6 } & $\mathbf{M}_{\mathbf{1}}$ & $\mathbf{M}_{\mathbf{2}}$ & $\mathbf{M}_{\mathbf{3}}$ & $\mathbf{M}_{4}$ & Control \\
\hline \multirow{2}{*}{ BAP } & 3.0 & 3.5 & 3.5 & 3.5 & 0.0 \\
NAA & 1.0 & 0.0 & 0.5 & 1.0 & 0.0 \\
\hline
\end{tabular}

Ten replicates were used for each media combination and sub-culturing was carried out at four weeks interval on the same media for consecutive sixteen weeks. All cultures were examined weekly and the effects of different media combinations were determined based on the number of shoots and the shoot height.

Sub-cultures were maintained under controlled conditions (24-26 ${ }^{\circ} \mathrm{C}$ of temperature and $75-100 \% \mathrm{RH})$ and white fluorescent light with $16 \mathrm{~h}$ of photo period for shoot multiplication.

\section{Statistical Analysis}

The data was analyzed using ANOVA in Complete Randomized Design (CRD) with ten replicates. Statistical Analysis System (SAS) 9.3 computer package was used to analyze the data. Significant differences between means were addressed using Ducan's multiple range test (DMRT) at 5\% probability level.

\section{RESULTS AND DISCUSSION}

Young shoot buds of meristems were used in this study and these were surface sterilized using the protocol shown in Figure 1 and Table 1.

In the present study, meristem explants showed lowest contamination percentage (18.2\%) in $\mathrm{T}_{3}$ (70\% ethanol [ $2 \mathrm{~min}$ ], $25 \%$ $\mathrm{HgCl}_{2}$ [15 $\mathrm{min}$ ], 20\% $\mathrm{NaOCl}$ [10 $\mathrm{min}$ ]), compared to the $\mathrm{T}_{1}(70 \%$ ethanol [1 $\mathrm{min}$ ], $15 \% \mathrm{HgCl}_{2}$ [15 min], 20\% $\mathrm{NaOCl}$ [10 min]) $(36.4 \%)$ and $\mathrm{T}_{2}(70 \%$ ethanol [1.5 $\mathrm{min}]$, $20 \% \mathrm{HgCl}_{2}$ [15 min], 20\% $\mathrm{NaOCl}$ [10 min]) which was $54.55 \%$ after one week (Figure 2). Most of the contamination was caused by bacteria and few fungi infections were also found. Establishment of contamination free cultures is the most difficult task when the explants are taken from the underground rhizome. 
Disinfecting with $70 \%$ ethanol prior to soaking in $\mathrm{HgCl}_{2}$ enhances the contact between $\mathrm{HgCl}_{2}$ and the surface of explants efficiently. Smith (2005) reported that $\mathrm{Hg}^{2+}$ in $\mathrm{HgCl}_{2}$ solution can break the structure of the cell membrane and the cytoplasm constituents of pathogenic microorganisms by interfering the enzymes and also the protein molecules. Sundram et al., (2012) reported that the concentration of $\mathrm{HgCl}_{2}$ was not increased more than $0.3 \%$ as high concentration of $\mathrm{HgCl}_{2}$ was phytotoxic to plant cells in soft tissues in his experiments. However, in the present study, explant source is underground stem part and lower concentrations of $\mathrm{HgCl}_{2}$ were not effective.

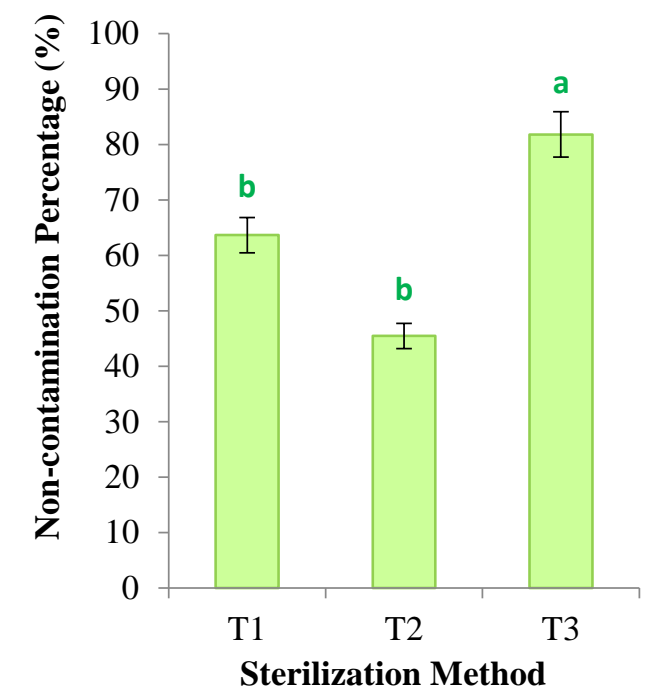

Means with different letters are significantly different at $\alpha=0.05$

Figure 2. Percentage of non-contaminated meristem explants observed under different treatments of the surface sterilization protocol (after one week).

Contamination in plant tissue culture can originate from two sources; either through carry-over of microorganisms on the surface or in the tissues. Therefore depending on the explant used, surface and endophytic microorganisms may be carriedover into cultures. In meristem culture, most organisms will be eliminated whereas in leaf, petiole or stem explants, microbes in the tissues may be carried-over (Gray and Purohit, 1991).

Gray and Purohit (1991) described that explant used in initial culture is critical for organogenesis. Although leaves, petioles and ovules have successfully been used for callus induction, for shoot initiation there are more factors to be considered. According to Xiuli et al. (2008) the main factors that affect shoot organogenesis are genotypes, explants and plant growth regulators.

In general, it is accepted that contamination of plant tissue cultures can be caused mainly by insufficient aseptic techniques during manipulations, incomplete surface sterilization of the explant and endogenous micro-flora present in the explant. In this experiment, the responses of the explants varied due to the changes of the soaking time and concentration of disinfectants.

The surface sterilized meristem and apical buds were used for shoot initiation in MS media supplemented with combinations of BAP with NAA in different concentrations mentioned in the Table 2 . The explants were turned into pale greenish at the end of the first sub-culturing stage and emerging shoots were observed at the base of the buds. Number of shoot initiated and 
the height of the emerged shoots were measured, after every four weeks of culturing to identify best hormonal combination for shoot initiation. However, there was no any shoot initiation in hormone free medium (control) at any sub culturing stage during the study period. At the first sub-culturing stage there was no any significant difference observed between the mean number of shoots and the different growth media (Figure 3).

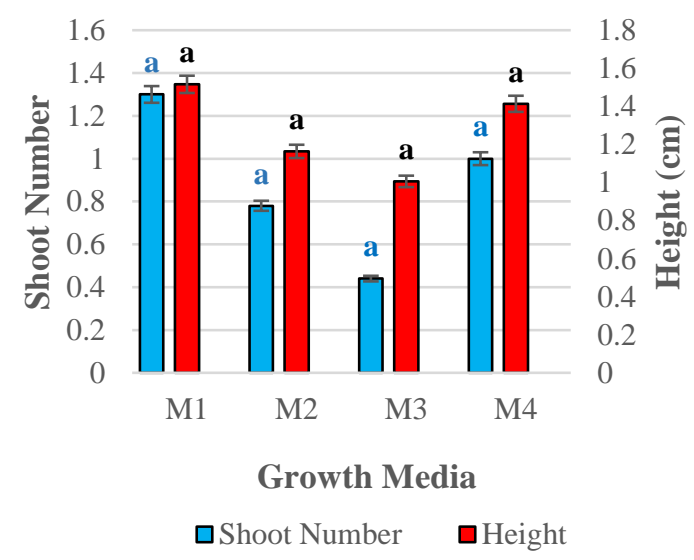

Means with different letters in each category of columns are significantly different at $\alpha=0.05$

Figure 3. Effect of growth hormonal combination for number of shoots and plant height $(\mathrm{cm})$ in the first sub-culturing stage

At the second sub-culturing stage, the difference was again not significant, however $\mathrm{M}_{4}$ media (BAP - $3.5 \mathrm{mgL}^{-1}$, NAA - $1.0 \mathrm{mgL}^{-1}$ ) generated the highest number of shoots ( 7 shoots) at the $2^{\text {nd }}$ sub-culturing stage whereas $\mathrm{M}_{2}$ (BAP- $3.5 \mathrm{mgL}^{-1}$ ) and $\mathrm{M}_{3}$ (BAP- $3.5 \mathrm{mgL}^{-1}$, NAA- $0.5 \mathrm{mgL}^{-1}$ ) resulted the same number of shoots. The lowest number of shoots (3 shoots) was obtained from the $\mathrm{M}_{1}$ medium (BAP- $3.0 \mathrm{mgL}^{-1}$, NAA- $1.0 \mathrm{mgL}^{-1}$ ) (Figure 4).
As shown in Figure 5, similar results were obtained for number of shoots in third sub-culturing stage where $\mathrm{M}_{4}$ media (BAP$3.5 \mathrm{mgL}^{-1}$, NAA- $1.0 \mathrm{mgL}^{-1}$ ) showed the highest number of shoots (7 shoots) which was significantly higher than the $\mathrm{M}_{1}, \mathrm{M}_{2}$ and $\mathrm{M}_{3}$ media.

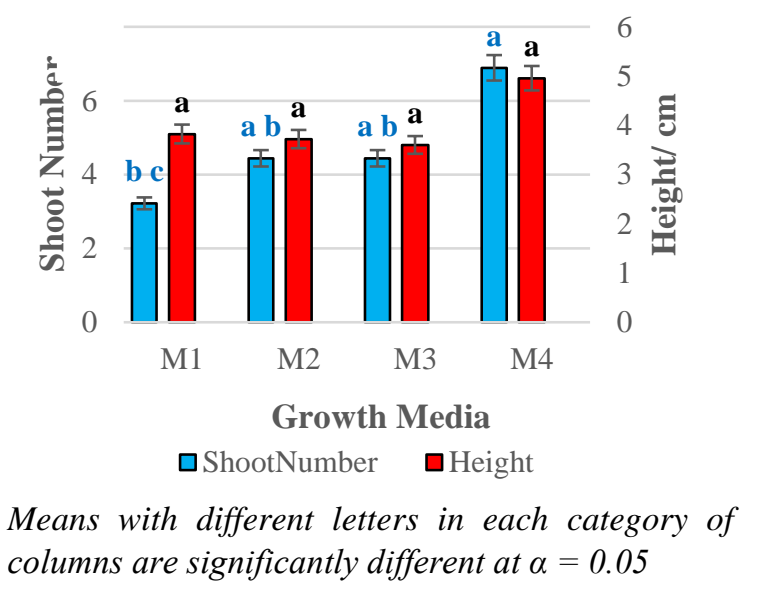

Figure 4. Effect of growth hormonal combination for number of shoots and plant height $(\mathrm{cm})$ in the second sub-culturing stage.

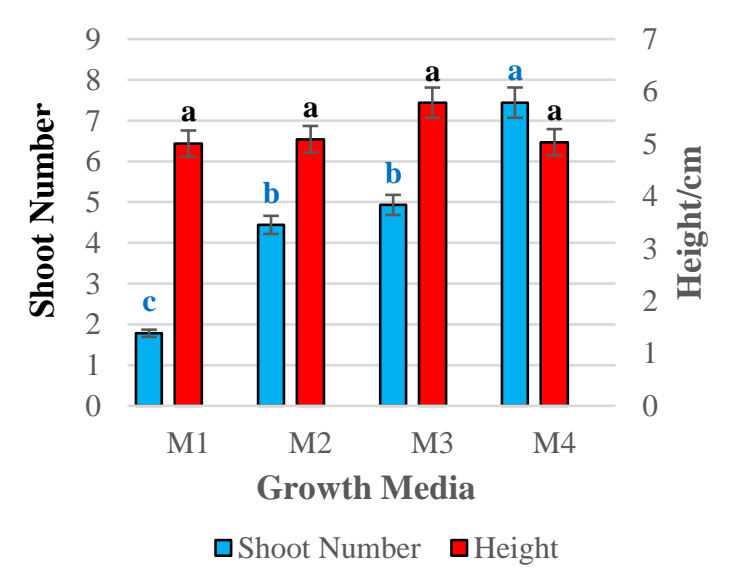

Means with different letters in each category of columns are significantly different at $\alpha=0.05$

Figure 5. Effect of growth hormonal combination for number of shoots and plant height $(\mathrm{cm})$ in the third sub-culturing stage 
At the fourth sub-culturing stages (Figure 6), $\mathrm{M}_{4}$ medium (BAP- $3.5 \mathrm{mgL}^{-1}$, NAA- $1.0 \mathrm{mgL}^{-1}$ ) was generated the highest mean number of shoots (12 shoots). The lowest mean number of shoots ( 5 shoots) was obtained from the $\mathrm{M}_{1}$ medium (BAP$3.0 \mathrm{mgL}^{-1}$, NAA-1.0 $\mathrm{mgL}^{-1}$ ) as illustrated in Figure 6 . There is no significant difference reported among media $\mathrm{M}_{2}, \mathrm{M}_{3}$ and $\mathrm{M}_{4}$. Among the tested culture media, $\mathrm{M}_{4}$ medium is the best to be used as multiplication medium for in-vitro propagation of C. ornata.

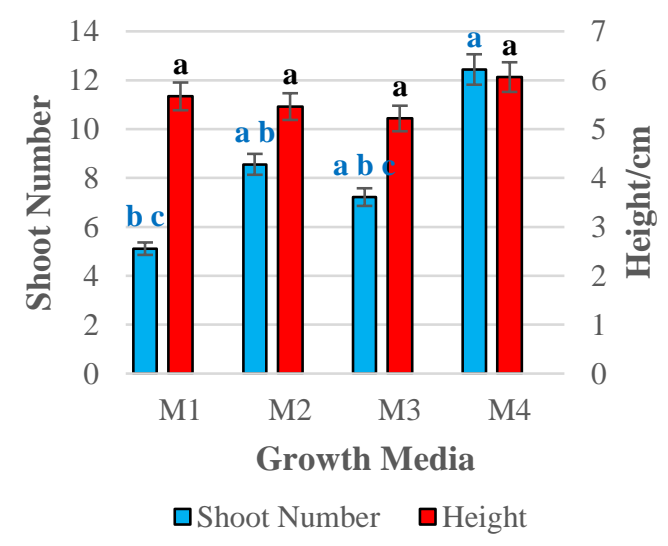

Means with different letters in each category of columns are significantly different at $\alpha=0.05$

Figure 6. Effect of growth hormonal combination for number of shoots and plant height $(\mathrm{cm})$ in the fourth sub-culturing stage

Appearance of the shoots after fourth sub- culturing cycle is shown in Plate 02. According to the results on height, it indicated that there was no significant difference among the shoot heights at any growth hormonal combination during each sub-culturing stage.

The lowest, mean height of the shoot $(1.0 \mathrm{~cm})$ was observed in the first sub- culturing stage in the $\mathrm{M}_{3}$ medium (BAP- 3.5 $\mathrm{mgL}^{-1}$, NAA- $0.5 \mathrm{mgL}^{-1}$ ) (Figure 3). The maximum, mean height of the shoot (6.0 $\mathrm{cm}$ ) was obtained at the fourth sub-culturing stage in the $\mathrm{M}_{4}$ growth medium (BAP- 3.5 $\mathrm{mgL}^{-1}$, NAA- $1.0 \mathrm{mgL}^{-1}$ ), however, no significant difference in plant height was recorded among the three media $\mathrm{M}_{1}, \mathrm{M}_{2}$ and $\mathrm{M}_{3}$ (Figure 6).

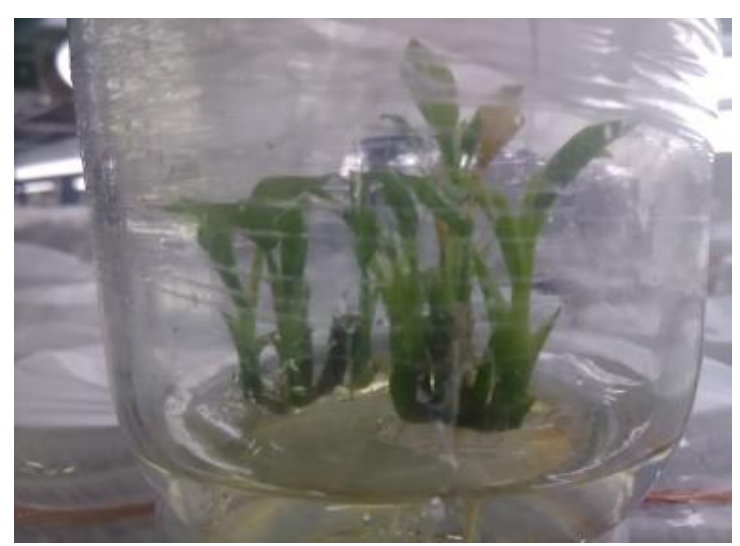

Plate 2. Shoots obtained at fourth sub culturing cycle.

\section{CONCLUSION}

Calathea ornata could be successfully surface sterilized with minimum contamination percentage when ex-plants treated with $70 \%$ ethanol for $2 \mathrm{~min}, 25 \%$ $\mathrm{HgCl}_{2}$ for $15 \mathrm{~min}$, followed by $20 \% \mathrm{NaOCl}$ for $10 \mathrm{~min}$. This study indicates that fast shoot induction with high number of shoots was obtained from explants cultured in the MS medium supplemented with $3.5 \mathrm{mgL}^{-1}$ BAP and $1.0 \mathrm{mgL}^{-1}$ NAA. The overall results of the study demonstrated that this shoot induction protocol could commercially be effective in terms of reduction of contaminations and production of multiple shoots in a short period of time. 
G. H. N. Maheepala, D. de Silva, P. E. Kaliyadasa and G. Y. A. D. D. Perera

\section{REFERENCES}

Anon, (2003). Regeneration of Begonia hiemalis in vitro. Acta Hortic, 64: 318.

Betrock, I. (1996). Plant finder. Betrock Information System, Hollywood, FL.

Chen, J., Henny, R. J. and McConnell, D. B. (2002). Development of new foliage plant cultivars. In: J. Janick and A. Whipkey (Editors). Trends in new crops and new uses, Timber Press, Inc: Portland, OR, 446-452.

Chen, J., McConnell, D. B., Henny, R. J. and Norman, D. J. (2005). The foliage plant industry. In: J. Janick (Editor) Horticultural Reviews, 31, John Wiey and Sons: NY, 45-110.

Daquinta, M., Brown, K., Teixeira da Silva, J. A. and Sagarra, F. (2009). In vitro propagation of arrowroot (Maranta $\begin{array}{lll}\text { arundinacea } & \text { L.). International }\end{array}$ Journal of Plant Developmental Biology, 3(1): 15-17.

Dunston, S. and Sutter, E. (1984). In vitro propagation of prayer plants. HortScience, 19: 511-512.

Gray, D. J. and Purohit, A. (1991). Somatic embryogenesis and development of synthetic seed technology. Crit. Rev. Plant Sci. 10:33-61.

Griffith, L. P. (1998). Tropical foliage plants: A grower's guide, Ball Publications, Batavia, IL.

O'Riordain, F. (1999). Directory of European plant tissue culture laboratories. COST Action, vol. 822. Brussels: Commission of the European Communities.

Podwyszy'nska, M. (1997).
Micropropagation of Calathea ornata Koern Biologia Plantarum, 39(2): 179-186.

Scaramuzzi, F. and Apollinio, G. (1997). Micropropagation of Ctenanthe lubbersiana Eichl. and Maranta leuconeura Morren var. Tricolor (Marantaceae). In: H. Bajaj (Editor) High-Tech and Micropropagation VI (Vol 40), Springer-Verlag,Berlin, 8595.

Smith, R. H. (2005). Plant Tissue Culture: Techniques and Experiments, Elsevier, New Delhi, India.

Sundram, T. C. M., Annuar, M. S. M. and Khalid, N. (2012). Optimization of culture condition for callus induction from shoot buds for establishment of rapid growing cell suspension cultures of mango ginger (Curcuma mangga). Australian Journal of Crop Science, 6(7): 1139-1146.

Van-Mil, A. and Van-Telgen, H. J. (1990). Micropropagation of Calathea ornate, In: $7^{\text {th }}$ International Congress on Plant Tissue and Cell Culture, Amsterdam, Netherlands.117.

Xiuli, S., Michael, E. and Jianjun, C. (2008). Effects of genotype, explant source, and plant growth regulators on indirect shoot organogenesis in Differenbachia cultivars. Available from: https://www.google.com/search $\mathrm{q}=x i u l i s h e n r e s e a r c h p a p e r$ (Accessed: 10 September 2018).

Yang, X. H., Liu, G. S. and Zhu, L. (1998). Cut flower production in China. In: M. K. Papademetriou and N. Dadlani (Editors), Cut Flower in Asia, RAP Publication, Asia, 85. 